\title{
História e geografia na sala de aula: a construção do conhecimento a partir da problematização da imprensa através do caso Sacco e Vanzetti
}

\author{
History and geography in the classroom: the knowledge construction \\ problems from the press through Sacco-Vanzetti case
}

\author{
Eduardo da Silva Soares \\ Universidade Federal de Santa Maria - UFMS - Santa Maria - Rio Grande do Sul - Brasil

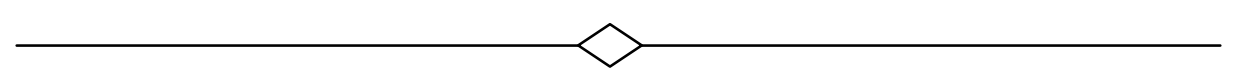

Resumo: Este artigo colabora com o debate sobre a importância da utilização dos recursos virtuais para o conhecimento histórico e geográfico. Portanto, foi questionada a utilização de sítios virtuais que disponibilizam jornais, dos anos 1920, e que transmitiram as informações oriundas das agências internacionais de notícias. Para isso, foram realizadas pesquisas, iniciando, com o levantamento de conteúdos a respeito da história das agências de notícias, problematizando o tipo e a qualidade das notícias publicadas nos jornais da época. O foco foi o caso Sacco e Vanzetti, ocorrido nos Estados Unidos da América. As notícias do caso foram difundidas entre os maiores meios jornalísticos e entre os jornais anarquistas brasileiros do período. Então, partiu-se de dois pontos objetivos: 1) as possibilidades de discutir o caráter dos conteúdos e; 2) os seus impactos entre os brasileiros. A principal fonte é o jornal, havendo, também, a utilização de outras fontes. A construção deste saber visa ser levado para a sala de aula, em uma escola de Cachoeira do Sul, denominada, Escola Municipal de Ensino Fundamental Imperatriz Leopoldina. E, por último, as pesquisas sobre o caso Sacco e Vanzetti estão incorporadas no projeto de doutorado vinculado ao Programa de Pós-Graduação em História da UFSM, existindo, então, a relação de dois espaços que propõem a construção do saber.

Palavras-chave: Ensino de História e Geografia. Caso Sacco e Vanzetti. Estudo de caso.

\begin{abstract}
This article contributes to the debate on the importance of the use of virtual resources to the geographical and historical knowledge. So it was questioned the use of virtual sites that offer newspapers, 1920, and transmitted the information from international news agencies. For this, research has been done, starting with the collection of content about the history of news agencies, questioning the type and quality of the news published in the newspapers of the time. The focus was the Sacco and Vanzetti case occurred in the United States, the case reports were disseminated among the largest Brazilian news media of the period. So it started with two goals points: 1) whether to discuss the nature of the content and; 2) its impact among Brazilians. The main source is the paper, there is also the use of other sources. The construction of this knowledge is intended to be brought into the classroom in a school in Cachoeira do Sul, called, Municipal School of Basic Empress Leopoldina Education. And lastly, research on the Sacco and Vanzetti case are incorporated into the doctoral project linked to the Graduate in History of UFSM program, there then the two spaces relationship that proposes the construction of knowledge.
\end{abstract}

Keywords: Teaching History and Geografhy; Sacco and Vanzetti case; Case study. 


\section{Introdução}

A construção do conhecimento histórico e geográfico não pode ser limitada a um único espaço, seja na academia, seja nas escolas de ensino fundamental e médio. Destarte, propõe-se problematizar um fragmento da pesquisa de doutorado do docente em relação aos conteúdos estudados por um grupo de estudantes. A conciliação dos saberes idealizados entre os dois pólos de conhecimento é imprescindível para melhorar o ensino geral. Portanto, aqui, o objetivo visou problematizar esta possibilidade e, de caráter específico, compreender a elaboração dos conteúdos e a importância das notícias transmitidas por jornais e agências especializadas para a informação dos brasileiros.

De qualquer forma, iniciou-se este artigo compreendendo a necessidade de transmitir os conceitos aqui abordados. Sendo o primeiro, a categoria agência de notícias, que pode ser definida como instituições associadas:

ao papel e caracterizados por uma audiência mais passiva, que esperava pelo jornal na manhã seguinte [...] para obter notícias e para se informar sobre assuntos que já teriam acontecido, mas que levavam o seu tempo a ser preparados em cada redação.

[...] neste contexto que atuavam também as agências de notícias, no fornecimento de notícias aos principais meios de comunicação social, para que estes as pudessem utilizar em diferentes momentos informativos (CARDOSO et. al., 2016, p. 4).

Diferente de hoje, nos anos 1920, considerando aqueles que sabiam ler, encontravam informações prontas, com as características orientadas pelos editores e redatores dos jornais impressos em folha papel. Muitos jornais já possuíam os contatos com as agências de notícias internacionais e mantinham a publicação periódica. Elas enviavam os informes do que ocorria e que motivação possuía. Os jornais brasileiros, em sua grande parte, construíam e transmitiam as suas opiniões inspiradas nas agências de notícias internacionais.
A função elementar das agências é, assim como Boyd-Barrett \& Rantanen (2004), Mattelart (1994) e Paterson (2005) defenderam, a importação e exportação do conteúdo jornalístico, preferencialmente aquele de origem internacional, não se limitando as fronteiras nacionais. Outra característica citada pelos autores é a consideração que a gênese das agências está relacionada com os serviços de informações financeiras para bancos, capitalistas e investidores nos grandes centros europeus, do século XIX. Deste modo, esse papel social evidencia a noção de que o "jornalismo nasceu internacional" (NATALI, 2004, p. 13).

Sendo assim, o jornalismo brasileiro preocupava-se com "o que acontecia lá fora", e, também, em relatar o que ocorria nas cidades que tinham sede. Considerando a primeira preocupação, neste contexto, os periódicos brasileiros buscavam as informações internacionais através das agências de notícias, o que não motivou a criação de agências nacionais (AGUIAR, 2008). Os jornais, neste universo, eram os mensageiros redigidos pelos escritores e conferidos pelos editores. Estes profissionais, os ditos jornalistas, viviam "escrevendo do mundo para o Brasil ou para o mundo sobre o Brasil" (AGUIAR, 2009, p. 2).

O leitor, sujeito passivo desta relação, teria que problematizar questionando aqueles dizeres, ou, viveria sustentando o senso comum emitido pelos periódicos. Os anarquistas e comunistas criticaram e produziram a sua imprensa, que não são tratadas neste artigo, pois, se fosse, significaria alargar em demasia os objetivos centrais desta produção. Aqui, foram limitados apenas aqueles maiores, tais como 0 grupo Folha de São Paulo e do Rio de Janeiro: O Jornal, a Gazeta de Notícias, o Correio da Manhã, O imparcial e o Jornal do Brasil.

Já sobre o caso Sacco e Vanzetti, este foi um fenômeno estadunidense ocorrido entre 1920 e 1927, respectivamente, ano da prisão e da execução. Eles eram italianos, anarquistas e trabalhadores não especializados. A condição de imigrantes e contestadores sustentou uma vasta literatura que 
analisou este caso. O "perigo vermelho" era sentido e temido desde a revolução de Outubro de 1917, na Rússia. Sem negligenciar que as insurreições e revoltas dos populares na Europa não deveriam serem esquecidas, elas, na atual conjuntura, alertariam os capitalistas no sentido de que era necessário manter o status quo de todas as formas possíveis.

O medo anarquista e da ameaça que os estrangeiros representavam motivou a perseguição contra inúmeros imigrantes nos Estados Unidos da América. No Brasil houve um processo similar, havendo, em 1907 a Lei Adolpho Gordo, que regulamentava a entrada, a detenção e a deportação dos "indesejáveis" da república. Nicola Sacco e Bartolomeo Vanzetti poderiam ser considerados os indesejados da "América". Porém, ao mesmo tempo que existia a ênfase condenatória no jornalismo estadunidense, se deu a defesa deles pelos órgãos dos trabalhadores. Puglielli (2013), Fast (2009) e Russell (1966) verificaram o caso e evidenciaram que a imprensa exercia forte influência na opinião pública local contra os anarquistas.

A problematização da história ocorre no sentido da construção de "um diálogo entre o presente e o passado, e não [de] reproduzir conhecimentos neutros e acabados sobre fatos que ocorreram em outras sociedades e outras épocas" (SCHMIDT, CAINELLI, 2009, p. 56). A necessidade por colaborar para a criticidade dos estudantes deve movimentar o professor, deve instigá-lo a procurar por novos métodos, fontes e a levar este acervo para o conhecimento e problematização dos alunos.

Outro conceito pontual é o fato histórico. Este conceito remete a percepção da amplitude da concepção de documento histórico, da crítica a ele e a construção do conhecimento sobre o passado a partir deles.

Os fatos históricos são cognoscíveis cientificamente, mas essa exigência deve levar em conta seus caracteres específicos. Por um lado, os fatos históricos são contraditórios como o próprio decorrer da história; eles são percebidos diferentemente (porque ocultados) segundo o tempo, o lugar, a classe, a ideologia. Por outro, escapam à experimentação direta por sua natureza passada; são suscetíveis apenas de aproximações progressivas, sempre mas próximas do real, nunca acabadas nem completas (CHESNEAUX, 1995, p. 67).

Percebendo o que é o fato histórico, estimulase a especulação a respeito do cotidiano experimentado pelo objeto do conhecimento, no caso, Nicola Sacco e Bartolomeo Vanzetti, na condição de mártires sociais. Neste sentido, eles estavam presos, condenados e tinham contatos através de cartas com os seus amigos e familiares. Eles possuíam interesses e enfrentaram as barreiras estruturais e conjunturais nos EUA. Assim, Cabrini et. al (1987), sustenta que "é importante que se faça com que o objeto de estudo apareça em todas as suas mediações e contradições", e, mais, "é importante que se tente reconstruir sua razão de ser a partir de sua própria natureza, fazendo emergir toda a trama de relações sociais que o constitui". Esta percepção é necessária, pois, os estudantes possuem um "conjunto de representações que ele já construiu acerca do mundo em que vive e que traz para a sala de aula" (SCHMIDT, CAINELLI, 2009, p. 83). Portanto, as ideias que eles construíram sobre "o mundo social - o significado de economia, família, poder -, as quais foram sendo construídas em sua própria história de interações social e cultural”, seja na família, ou, entre amigos, os fazem emitir valores. Cabe ao historiador e ao geógrafo desconstruir o senso comum, estimulando, através da construção do conhecimento, a elaboração de opiniões formadas a respeito dos assuntos abordados, neste caso de estudo, a imprensa.

Deste modo, pensa-se que seja essencial construir conceitos com os estudantes. Este é um processo cognitivo que "eles articulam-se, contrapõem-se e associam-se de forma solidária, pela acomodação e pela sua relação dialógica com um campo de conhecimento, uma relação com as representações já elaboradas pelos alunos, para modificá-las" (SCHMIDT, CAINELLI, 2009, p. 85). Modificando as relações dos estudantes com o 
mundo de teorias e reflexões por eles construídas, consegue-se problematizar a opinião emitida pelos órgãos de comunicação. Em uma visão extremamente otimista, é possível criar o senso crítico em relação aos discursos da imprensa ligada aos partidos, movimentos sociais e grupos empresariais.

Nesse sentido, o processo de construção de conceitos históricos é parte do fenômeno denominado captura lógica das propriedades e dos fenômenos do mundo social e parte da sua articulação num contexto de conhecimentos e cultura ao qual pertence o aprendiz. Nesse caso, o pressuposto fundamental é a constatação de que os conceitos devem ser elaborados e sistematizados pelo aluno e, para serem trabalhados em sala de aula, é imprescindível a utilização de linguagem acessível a sua maneira de pensar, a seu vocabulário, a seu desenvolvimento intelectual e a sua cultura experiencial (SCHMIDT, CAINELLI, 2009, p. 85).

É necessário fazer pensar sobre as perspectivas de mundo diferentes daquelas dos alunos. A construção do conhecimento deve partir do pressuposto que existe a necessidade de entender as diferenças de pensamento entre as pessoas. O espaço social é compartilhado, e, por isso, há a cautela de criar argumentações em sala de aula que visam o respeito na sociedade.

Sacco e Vanzetti ocuparam espaços que modificaram as suas experiências. A Itália com as suas paisagens e lugares. A viagem para os Estados Unidos da América, somado as novas possibilidades de vida. E, por fim, o cárcere e a concepção da privação do convívio social. Se, a ideia de espaço social for pensada conforme Henri Lefbvre (1991), existem "três momentos de espaço social", ou seja, o espaço concebido, o espaço percebido e o espaço vivido. Se, o espaço concebido faz jus ao acúmulo intelectual do conhecimento, o espaço percebido inclui as práticas espaciais e os sentidos como "base prática da percepção do mundo exterior" (p. 40). Enquanto isso, o espaço vivido é experimentado por meio de imagens e símbolos, de forma representacional, recebido de forma que "a imaginação procura mudar e apropriar" (p. 39).

As formas de pensar e de escrever, ilustrando as experiências, os lugares e as paisagens, são bons exemplos para demonstrar as representações de mundo existentes. Além do mais, é uma grande ajuda para a problematização do como o "modo de produção organiza - produz - ao mesmo tempo que certas relações sociais, seu espaço (e seu tempo)" (LEFEBVRE, 2006, p. 8). Assim, o capitalismo subjuga os agentes sociais e os condena a uma situação: trabalhar para sobreviver. E, esta foi uma das denúncias realizadas pelos italianos anarquistas aqui trabalhados.

As trajetórias destes italianos servem de exercício para a verificação das migrações ocorridas no início do século XX. Nas cartas que eles escreveram, são encontrados exemplificações que orientam o leitor a perceber o lugar de origem, a transição da Itália para os Estados Unidos da América e as suas primeiras impressões no continente americano. A infância, a formação intelectual, as primeiras experiências de trabalho, a prisão e a morte. De imigrantes dotados da esperança de uma vida melhor para as páginas dos jornais como injustiçados, ou, até, mártires das reivindicações libertárias. Todos estes elementos são passíveis de serem historicizados.

Procurando transformar as ideias em uma exposição didática, propõem-se dois capítulos para a elaboração das ideias propostas neste artigo. No primeiro, fala-se do caso Sacco e Vanzetti. No segundo foram utilizados os recursos virtuais disponibilizados na internet para a consulta aos/nos periódicos existentes, que foram abordados como possibilidades de estudos e problematizações a respeito da circulação de notícias e (pelos) jornais do início do século $X X$.

\section{0 curioso caso Sacco e Vanzetti}

Bartolomeo Vanzetti nasceu no dia 11 de junho de 1888, em Villafalletto, província de Cuneo, 
Piemonte, Itália. A população de Villafalletto era tipicamente camponesa. Foi, ainda neste local, que Vanzetti passou a sua infância, e, até os 13 anos, estudou. Em seus relatos, foi descrita a presença da dúvida de seu pai, o qual "não sabia" se permitia que o filho seguisse os estudos ou se o ensinava algum ofício. O seu destino, traçado pelo pai, foi ser comerciante na cidade de Cuneo, em 1901.

Após, teve uma ida frustrada para Turim, o que Ihe forçou a retornar à cidade natal. Nesta etapa, acompanhou a mãe enferma até a morte. Em 1908, deixou os seus familiares, e, todos ficaram transtornados com dois fatos: a perda da matriarca e a emigração de Vanzetti. Escreveria: "Assim deixei a terra que me viu nascer; um vagabundo sem pátria" (VANZETTI, 2011, p. 30).

Com tristeza e amargura, Vanzetti viajaria em um trem durante dois dias e, mais sete, em um vapor pelo mar à "terra prometida"1 (VANZETTI, 2011, p. 30). Ao chegar em Nova York, percebeu que ela "se destacava no horizonte com todos os seus esplendores e esperanças" (VANZETTI, 2011, p. 30). Porém, desde a sua primeira experiência ocorreram as adversidades que minariam a sua existência nos Estados Unidos da América:

\begin{abstract}
Na estação de imigração tive minha primeira grande surpresa. Vi os passageiros de proa serem manuseados pelos oficiais da mesma forma que um montão de animais. Nenhuma palavra de benevolência ou de estímulo que aliviaria a aflição que agoniava pesadamente aos recém-chegados as praias da América. As esperanças que levavam a estes imigrantes até a nova terra, se marchetavam assim ao contato de torpes oficiais (VANZETTI, 2011, p. 30).
\end{abstract}

Eles procuravam por empregos e melhores qualidades de vida. $\mathrm{Na}$ oportunidade de "fazer à América" foi que Sacco e Vanzetti se apoiaram. Pois bem, no caso de Vanzetti, por 12 anos ele trabalhou e viveu livremente naquele país, até que, em 1920, seria preso por mais 7 anos.

Durante os anos de liberdade, Vanzetti foi um militante ativo. Mais tarde, em seus escritos, ele

\footnotetext{
${ }^{1}$ Palma e Truzzi (2014, p. 75) defenderam que "fazer a América!" foi uma expressão reproduzida por muitos dos migrantes que foram para o continente americano.
}

declararia o seu posicionamento político e as participações que manteve nas greves e nas agitações operárias. O seu sonho era o de mudar a sociedade, o que significa afirmar que ele desejava a anarquia como sistema. Foi este fator que acarretou na sua prisão ${ }^{2}$. Na verdade, segundo o próprio, além de anarquista, pesava sobre ele o fato dele ser italiano e pobre.

O processo de Plymouth foi que condenou a dupla italiana à cadeira elétrica. O Estado o condenou, segundo as palavras de Vanzetti (2011, p. 67), "por roubo e assassinato". Nos seus escritos foi possível encontrar argumentos que referenciavam o Estado como o responsável pela sua suspeita. O crime de assalto e assassinato, que ocorreu no estado de Massachusetts, em Bridgewater, no dia 24 de dezembro de 1919, chocou a população local. Este fator colaborou para a execução final, porém, até este momento, a defesa de Sacco e Vanzetti utilizou de inúmeros argumentos, e, a primeira consideração foi: "no dia 24 de dezembro de 1919, enquanto eu vendia enguias em Plymouth" (VANZETTI, 2011, p. 30), não poderia, de fato, estar presente na cena do crime, já que os seus álibis defendiam um grande distanciamento do local em que ele se encontrava em relação à fábrica assaltada.

Vanzetti esclareceu que comer peixes e enguias fazia parte de "uma antiga tradição" italiana. Esta "tradição" justificaria a sua saída vendendo estes produtos. Então, segundo Vanzetti, foram feitos muitos pedidos para ele, e, para que satisfizesse a demanda, ele teve "que trabalhar durante todo o dia de 24 de dezembro e efetuar este trabalho em Plymouth" (VANZETTI, 2011, p. 68). Vanzetti passou o dia trabalhando, exercendo a sua profissão e

\footnotetext{
2 Flavia Tudini (2013) apontou com clareza que eles eram conhecidos pelas autoridades policiais por causa de suas posturas políticas. A autora argumentou que a publicização do caso Sacco e Vanzetti foi uma estratégia da defesa para acumular forças junto a opinião pública, em outras palavras, através da pressão popular, a defesa desejava levar o caso para a Corte Suprema dos Estados Unidos da América, e, nesta instância, comprovar a inocência ou conquistar uma pena mais amena. A defesa tornaria pública que a Justiça daquele país os condenava por causa da etnia e da orientação política, negligenciando a culpabilidade no crime na hora de conceber o parecer do julgamento.
} 
contribuindo para uma "antiga tradição" de seus conterrâneos. A materialização de sua defesa foi somada com a afirmação de que ele estava "a 30 milhas da cena do crime". No mais, "quando a colônia italiana se inteirou de que eu (Vanzetti) havia sido processado pelo crime de Bridgewater, proclamou minha inocência e ofereceu o seu testemunho".

Resultado, inicialmente, 30 "italianos se apresentaram ante o tribunal para provar meu álibi". Além disso, "poderiam haver sido mais, porém sua presença ali só seria cumulativa". Logo, uma sequência de nomes e profissões foi listada. Estas pessoas afirmavam a inocência de Vanzetti. Porém, a italianidade e as ideias que Vanzetti mantinha foram ferramentas de acusação do Estado. Então, o interrogador, ao "saber" que se tratava da investigação de um anarquista, "se serviu de tais informações para convencer o jurado de que meus álibis eram falsos, que meus amigos realizavam um esforço heroico para salvar-me" (VANZETTI, 2011, p. 69).

Quanto a Nicola Sacco, ele nasceu em Torre Maggiore, na província de Foggia, em 1891. Viveu com os pais e trabalhou com os irmãos até os 17 anos, na propriedade do pai. Porém, a situação financeira mudou com o tempo. A crise não perdoaria aquela família. Então, dos dias tranquilos aos dias da emigração, Sacco (2011, p. 42), escreveu:

[...] a precariedade na qual se bate a existência de todo pequeno proprietário da Itália, a curiosidade natural de todo adolescente, o desejo de afrontar o desconhecido, de experimentar sensações novas, de criar para si, por sua atividade, por sua clarividência, um mundo no qual cada um possa reivindicar seu direito natural a existência, me impulsionaram a emigrar.

A pobreza e o medo da miséria fizeram com que muitos italianos deixassem a sua terra. Milhares deles foram para a América, seja para os Estados Unidos da América, seja para a Argentina ou para o Brasil. O sonho de obter sucesso na "Terra Prometida" motivou muitos grupos destinados para outros países. Tudini (2013, p. 1) afirmou que a imigração italiana nos Estados Unidos da América, entre o final do século XIX e início do $X X$, mobilizou "cerca de 26 milhões" de pessoas, que, em sua maioria, não conheciam "a língua, eram católicos, pouco instruídos e ocupavam os níveis mais baixos do mercado de trabalho". Com exceção da religiosidade, Sacco e Vanzetti pareciam se enquadrar nas demais características dos imigrantes.

Dando sequência ao relato, ao chegar nos Estados Unidos da América ele era "quase ignorante das questões políticas e das múltiplas e multicores tendências" (SACCO, 2011, p. 42). Após a chegada dele, ocorrida em 1908, se passa um "ano terrível de desocupação, de miséria, de fome", desta maneira, "experimentei já minhas primeiras desilusões". Após este momento, Sacco inicia a sua militância de forma ativa. Um exemplo foi a resistência contra a Primeira Guerra Mundial organizada no país.

Neste período, pertenceu a Federação Socialista Italiana (SACCO, 2011). Casou-se com "Rosina" e teve o primeiro filho: Dante Sacco. Nicola Sacco organizava conferências, reuniões e lutava pela unidade dos trabalhadores. E, no dia em que organizava um meeting contra a prisão de Roberto Elia e Andrés Salsedo ${ }^{3}$, ele e Vanzetti (outro organizador do protesto) foram presos. Então, questiona: "de que era culpado? De um infame, de um atroz crime que meu cérebro não podia conceber". Destarte, sentenciou:

Meu crime, o único crime, de que estou orgulhoso, é o de haver sonhado uma vida melhor, feita de fraternidade, de ajuda mútua; de ser, em uma palavra, anarquista, e por este crime tenho o orgulho de terminar entre as mãos de verdugo. Porém que tenham logo a coragem de dizê-lo, de gritar ao mundo aos governantes e aos assalariados dos Estados Unidos - que havendo adquirido sua independência em nome da liberdade, eles pisoteiam essa liberdade em todos os atos de sua existência (SACCO, 2011, p. 43).

Uma questão pontual merece ressalva, mesmo que não conseguissem escapar da execução, desejavam que as suas ideias de emancipação social prosseguissem com outros agentes. O fim de Sacco e

\footnotetext{
3 No dia 4 de maio de 1920, Salsedo foi encontrado morto após ter sido detido e torturado no Departamento de Justiça de Nova York. Salsedo e Elia eram editores do jornal II Doman, um periódico anarquista.
} 
Vanzetti era frisado como "a batalha entre o rico e o pobre, a batalha pela salvação e pela liberdade que tu continuarás um dia" ${ }^{4}$ (SACCO, 2011, p. 134). "Tu continuarás" a luta pela liberdade dos povos, declarou um condenado por ser anarquista e italiano. Este desejo traduziu a posição ideológica seguida pelo autor. Este é o maior exemplo encontrado para frisar os seus posicionamentos e desejos de um porvir diferente.

Como mártires morreram, em 23 de agosto de 1927, mas, no último dia 4, Sacco escreveu: "agora, ignorando a consciência e negando todas as provas de nossa inocência, nos insulta e nos assassina. Somos inocentes!" (SACCO, 2011, p. 131). Sacco mostrava que estava inconformado com a situação e condena: "esta é a maneira de operar da plutocracia contra a liberdade, contra o povo. Nós morremos por ser anarquistas. Viva a anarquia!". A execução simbolizava a luta da burguesia contra o povo, contra aqueles que procuravam a emancipação social. E, mais, a cadeira elétrica matava dois anarquistas, sendo este o principal motivo daquela condenação, não conseguiam, de forma plena, matar este ideal. A anarquia continuaria viva entre os trabalhadores. Este foi o recado pronunciado por Sacco antes de morrer.

Sacco falou que a sua execução era esperada, já que "a classe capitalista é implacável e dura, e não tem clemência com os bons soldados da revolução" (SACCO, 2011, p. 131). A sua condenação tinha um significado implícito, os capitalistas, hegemônicos no Estado, controlavam e aniquilavam aqueles que contestavam tal domínio. Se necessário fosse, matariam os "bons soldados" contrários as suas políticas. A burguesia possuía os mecanismos e os utilizava sem receios. Quanto a Sacco e Vanzetti, "estamos orgulhosos de morrer e cair como todos os anarquistas tem caído e caem", agora, a missão de derrubar o sistema e implantar a anarquia ficava a cargo de "vós, irmãos, camaradas".

3 Meios, problemas e debates acerca do ensino de geografia e história em um estudo de caso

\footnotetext{
${ }^{4}$ No original o texto é destinado ao seu filho Dante Sacco, por isso a referência na segunda pessoa do singular "tu".
}

O problema está relacionado a investigação sobre os conteúdos das notícias referentes ao caso Sacco e Vanzetti que foram difundidas nos maiores meios jornalísticos brasileiros. Parte-se de dois pontos objetivos: 1) o caráter dos conteúdos e; 2) os seus impactos entre os brasileiros. A principal fonte foram os jornais. Então, deve ser realizada uma pesquisa nos sítios virtuais: da Hemeroteca Digital Brasileira $^{5}$ e do Grupo Folha de São Paulo.

O sítio da Hemeroteca Digital Brasileira contém, na sua apresentação, o seguinte enunciado: "portal de periódicos nacionais que proporciona ampla consulta, pela internet, ao seu acervo de periódicos jornais, revistas, anuários, boletins etc. - e de publicações seriadas". Sobre as possibilidades de consulta, há a descrição: "pesquisadores de qualquer parte do mundo passam a ter acesso, inteiramente livre e sem qualquer ônus, a títulos que incluem desde os primeiros jornais criados no país". A sua utilidade é de grande valia no ensino fundamental, já que através da consulta neste sítio é possível verificar os conteúdos, as diagramações, os contextos, as formas ortográficas e gramaticais, como também, possibilitar aos estudantes o contato produtivo com a internet. Esta proposta visa aperfeiçoar os instintos de pesquisadores dos estudantes.

Quanto à forma de acessar o acervo, o sítio diz que é "possível a partir de qualquer aparelho conectado à internet, é plena e avançada. Pode ser realizada por título, período, edição, local de publicação e palavra(s)". Na ferramenta de pesquisa, foi selecionado o período temporal de 1920 a 1929, em todos os periódicos do Brasil digitalizados pelo sítio, com Sacco e Vanzetti como palavras-chaves.

O resultado geral foi: 1671 ocorrências, em 447 bibliotecas, contando com 4.091.512 páginas. Os 5 jornais que tiveram mais ocorrências foram: 0 Jornal, do Rio de Janeiro; a Gazeta de Notícias, do Rio de Janeiro; Correio da Manhã, do Rio de Janeiro; O imparcial, do Rio de Janeiro; e o Jornal do Brasil, do Rio de Janeiro.

\footnotetext{
${ }^{5}$ Link: http://bndigital.bn.br/hemeroteca-digital/
} 
Outro sítio que é possível realizar consultas online é o do Grupo Folha ${ }^{6}$, do estado de São Paulo. A página avisa que a consulta é gratuita por um período de degustação. Porém, não existe o aviso sobre o período e nem as formas de cadastro possíveis para o seu controle. É citado que existem os direitos reservados, e que é "Proibida a reprodução do conteúdo em qualquer meio de comunicação, eletrônico ou impresso sem autorização da Folhapress"”.

Em relação à pesquisa com palavras-chaves, no acervo Folha são encontradas 351 páginas. A investigação teve Sacco e Vanzetti como palavraschave e os periódicos consultados desde 1921. Os jornais deste Grupo eram: Folha da Manhã e Folha da Noite. No ano de 1927 foram encontradas 71 páginas, concentrando-se mais no mês da execução, ou seja, em agosto.

Os conteúdos dos jornais, de forma geral, tendem a defender os italianos Sacco e Vanzetti, mas, por outro lado, criticam as ações "terroristas" que os anarquistas, ditos seus admiradores, realizavam. Foram encontrados anúncios publicados a partir das informações das agências de notícias que se referem aos atentados com dinamite em algumas cidades europeias. O anarquismo no "velho mundo" aterrorizava os países "civilizados". Era este o tom do discurso em relação aos anarquistas. Mas, sobre a condenação à morte, os periódicos eram afinados e concordavam que os "tempos atuais" não permitiam mais tais práticas. Destarte, no dia 20 de julho de 1927, na segunda página, o periódico carioca $A$ Manhã publicava um artigo sobre o temor da "vingança" do operariado internacional.

$\mathrm{Na}$ mesma nota, apareceu à afirmativa que dizia que Sacco e Vanzetti declaravam-se inocentes e vítimas de um erro judicial. Houve a asseveração a respeito da "exaltação dos ânimos" dos defensores dos italianos. E, findando a publicação, é apontado

\footnotetext{
${ }^{6}$ Link: http://acervo.folha.uol.com.br/

${ }^{7}$ Foi enviado um e-mail para a Folhapress requerendo as informações de como é feito para o devido cadastro para a obtenção da autorização para a publicação dos conteúdos dos jornais, porém, não foi obtido resposta.
}

um atentado com bomba na frente da Embaixada dos Estados Unidos da América, em Nice, na França.

Convém afirmar que todas as manifestações ocorreram no espaço da cidade ${ }^{8}$, pois, é nela que se concentram os poderes econômicos e políticos (LEFEBVRE, 2001). Então, o seu domínio pode ser exemplificada, problematizando o êxodo rural de Nicola Sacco, a imigração para a cidade e as manifestações serem descritas como urbanas. De todo modo, "a cidade é um grande sistema, produto de superposição de subsistemas diversos de cooperação, que criam outros tantos sistemas de solidariedade" (SANTOS, 2006, p. 219). No Brasil, na Europa e nos Estados Unidos da América, ocorreram manifestações solidariedade em prol de Sacco e Vanzetti, elas ocorriam através de comícios, passeatas e panfletagens nos espaços públicos, tais como as praças e vias centrais, em outros muitos casos, os sindicatos e espaços operários também receberam estas ações.

A importância de discutir a industrialização, as movimentações dos grupos sociais e as migrações estão relacionadas às problematizações sobre 0 desenvolvimento das cidades. A cidade enquanto espaço de disputa política é crucial para a formação dos estudantes. Neste estudo de caso, todos estes conceitos podem ser analisados.

As formas que ocorreram as emigrações da Itália e a imigração nos Estados Unidos são exemplos de "sonhos" e necessidades pecuniárias. Nos relatos que Sacco e Vanzetti deixaram, foi possível verificar as suas experiências nas viagens, desde os transtornos e dificuldades, até as esperanças de uma vida melhor. A partir do exemplo destes italianos, foi possível verificar as discussões a respeito da legitimidade da pena de morte. Neste sentido, os católicos, os republicanos e trabalhistas estavam de acordo: era necessário acabar com este sistema de penitência. Então, as formas como ocorriam às execuções e quais eram os crimes capitais podem se tornar um bom início de uma aula baseada nos direitos, jurisprudências e constitucionalidades destes tipos de condenações.

\footnotetext{
${ }^{8}$ No sentido estritamente urbano.
} 
As relações jurídicas e as e/imigrações não se encerram neste caso, neste exemplo, ele pode ser o ponto de partida para questões mais amplas, tais como a expulsão e deportação de estrangeiros. Destarte, qual a configuração do conceito estrangeiro, colono e (i)migrante? Pensando na realidade brasileira, é possível traçar um histórico da luta contra este tipo de leis, a citar, a Lei Adolpho Gordo, de 1907. Quais foram as formas de resistência e luta contra os aparelhos que promovem a opressão e a repressão? Os jornais anarquistas e operários podem apontar os indícios a serem debatidos.

Os movimentos migratórios que concentram colônias podem criar e fortalecer o senso de identidade étnica. Nas declarações de Vanzetti (2011), quando eles foram presos, 30 italianos foram testemunhar a seu favor. No mesmo documento ficou perceptível que a Justiça estadunidense rejeitou todos, seja pelo senso de defesa existente entre os italianos, seja pelas ideias anarquistas que a dupla defendia. As diferenças entre italianos e estadunidenses foram questionadas pelo autor. Tal discussão é imprescindível para os estudantes, pois, as levas migratórias que ocorrem contemporaneamente podem colocá-los em contato com vários grupos sociais, de etnias distintas das suas, ou não.

As diferenças políticas também podem ser verificadas, já que uma das motivações para a condenação parecia seguir neste sentido. Procurando estabelecer relações com a contemporaneidade, é possível construir argumentações a respeito da realidade atual do Brasil. Além do mais, pode ser debatida a construção das noções esquerda e direita política, e, as diferenças de concepções partidárias entre o Brasil e os Estados Unidos da América. As possibilidades de ensino na área do direito, da política e das migrações são variadas, conforme pôde ser visto.

Atualmente as discussões sobre o ensino de História e Geografia estão ganhando uma perspectiva nacional comum. Então, se faz necessário verificar o seu conteúdo e analisar as possibilidades de estudos. Além disso, uma justificativa para o estudo de caso pode ser encontrado na Base Nacional Comum

Curricular, publicada em 2016, na versão "revista":

Esse estudo favorecerá o exercício da cidadania na medida em que, comprometido com o caráter complexo e plural desses nexos, estimule e promova o respeito às singularidades étnico-raciais e culturais, e a liberdade de pensamento, de ação, de credo religioso, e de opções politicas. Em suma, a partir de procedimentos e temas selecionados, o estudo da História deve contribuir para a consciência de si e do outro, de modo que as identidades sociais possam, compreensivamente, se constituir na relação com outras, dadas em diferentes tempos e espaços sociais, e com elas conviver (BNCC, 2016, p. 155).

Respeitando as diferenças culturais, temporais e espaciais, deve-se discutir a ação do Estado enquanto regulador de ideias e concepções de mundo. No caso de Sacco e Vanzetti, eles eram estrangeiros e anarquistas. Eles poderiam ser considerados como os "indesejados" de um modelo social que visava à proteção dos privilégios dos capitalistas. No Brasil, na Primeira República, ocorreram prisões e deportações. Com os jogos olímpicos que ocorreram, em 2016, no Brasil, houve uma lista de ressalvas contra certos grupos estrangeiros, políticos e religiosos.

O Estado aparece como promotor da ordem, da lei, da proteção dos turistas e cidadãos brasileiros. Assim, seja nacional, seja estrangeiro, o Estado regulamentará e dirá quem pode assistir, e, até mesmo, quem pode permanecer no território. O modelo de cidadania entra em discussão, mas, infelizmente, muitas vezes a imprensa apenas descreve quem é "a figura do mal".

As diferenças de credo religioso são postos e comparados. As singularidades culturais do outro envolvem o preconceito étnico-racial, já que, ao transformar o outro em algo imaginado, preconcebido, ocorre a prisão dos "suspeitos" e o silêncio do discurso de defesa. A instauração do medo é uma estratégia discursiva muito eficiente. Portanto, o estudo de História deve contribuir para a problematização destes discursos generalizantes. O ensino de História e Geografia, ao propor o debate sobre terrorismo, pode comparar a imagem do 
terrorista atual com o do início do século passado, que de forma geral convém dizer, o anarquista e o muçulmano, respectivamente.

Sacco e Vanzetti realizaram uma luta contra a burguesia e o Estado. Os interesses das classes foram expostos nos seus discursos e, nos jornais anarquistas, essa constatação ficou evidente. Mas, nos periódicos de grupos de empresários, a defesa se voltava contra a sentença de pena de morte. De todo modo, é necessário identificar e perceber as jurisprudências dentro dos seus limites territoriais. Destarte, o estudo da Geografia colabora, já que "na Geografia, a compreensão do mundo passa pelo entendimento do Estado como organização sociopolítica e de seu papel na configuração do território, no reconhecimento das diversas territorialidades por ele abarcadas e na garantia de direitos da população" (BNCC, 2016, p. 160).

Outro conceito importante é o de migrações. Tanto a Geografia quanto a História se preocupam em estudar os grupos que migram de um lugar para outro. Neste sentido, Sacco e Vanzetti são exemplos daqueles que "fracassaram" no intento de "melhorar" de vida. Fracassam porque são presos e executados, eles não enriquecem e nem se tornam exemplos de milhares de imigrantes que se consolidam nos lugares de destino.

A pesquisa sobre a vida destes italianos possibilita investigar várias fontes: jornais da época ${ }^{9}$; cartas; fotografias ${ }^{10}$; discurso político $^{11}$; texto jurídico $^{12}$. Os meios para acessar tais documentos variam: internet e bibliografias impressas. Esta série

9 Os jornais podem ser acessados através das hemerotecas digitais mencionadas ao longo do texto.

10 Nas duas publicações existem fotografias das manifestações e dos acusados: PORTER, Katherine Anne. Sacco e Vanzetti: um erro irreparável. Rio de Janeiro, Salamandra, 1978. E RUSSELL, Francis. A tragédia de Sacco e Vanzetti. Rio de Janeiro: Editora Civilização Brasileira, 1966.

11 Dois exemplos de discursos políticos são o do vereador Alberto Silvares, do Rio de Janeiro, e, o segundo, o do deputado Azevedo Lima, ambos pronunciamentos realizados em 1927. Maiores informações ver: MOURA, Clóvis. Sacco e Vanzetti: o protesto brasileiro. São Paulo: Ed. Brasil Debates, 1979, p. 40-43.

12 Maiores informações ver: RUSSELL, Francis. A tragédia de Sacco e Vanzetti. Rio de Janeiro: Editora Civilização Brasileira, 1966, p. 101-224. de recursos é fundamental para a formação dos estudantes, pois eles conseguem conhecer e problematizar fontes que não são textos didáticos prontos, ou seja, surge a possibilidade da construção do conhecimento a partir das assimilações e criticas individual a cada documento. Destarte,

A incorporação de novos recursos de pesquisa, a consulta a fontes e documentos que circulam em esferas mais ampliadas, inclusive em ambientes virtuais, o trabalho com diferentes linguagens, devem permitir que os/as estudantes realizem análises e interpretações considerando múltiplas perspectivas sobre fatos e acontecimentos. A articulação da Historia com os componentes curriculares da área de Linguagens tem um importante papel nesse sentido, ao permitir que as diferentes fontes sejam lidas como documentos históricos mas, também, incorporando a essa leitura aspectos linguísticos, estéticos, afetivos, que permitam a produção de sentidos para os conhecimentos e informações acessados (BNCC, 2016, p. 461).

Pensando conforme Daniel Vieira Helene (2016), em sua tese, seria necessário ler, escrever, compreender as fontes, elaborar explicações e perceber-se como sujeito social. Todos estes princípios são, também, objetivos do ensinoaprendizagem da História. Conhecer as fontes do historiador favorece o desenvolvimento do senso critico dos próprios textos históricos. A produção e a critica em relação aos documentos utilizados para o fazer historiográfico é um dos alicerces do ensino de História, e, enfim, este fazer científico torna-se em "um importante papel para o alcance dos objetivos gerais de formação" (BNCC, 2016, p. 461) do educando. Ao transformarem-se em autores, eles aprendem a recortar, a escolherem, dimensionarem e narrar o passado enquanto agentes do presente, apontando assim, a representação "de um indivíduo sobre o passado" (KARNAL, 2010, p. 7).

Ao propor que os estudantes construam um olhar crítico sobre as instituições estatais e privadas, ressalva-se que "é preciso ter bem claro que devemos estar preparados para ocupar um espaço na sociedade globalizada" (PINSKY \& PINSKY, 2010, p. 21). Em outras palavras, torna-se necessário construir o conhecimento crítico, pontuando o processo 
histórico "para além da descrição factual e linear" (BEZERRA, 2010, p. 43) da História, assim, deve-se pensar nas "práticas, ordenadas e estruturadas de maneiras racionais".

Deste modo, além dos conceitos apontados, deve-se pensar na forma como as instituições funcionam. Necessita-se verificar as ações humanas de forma relacionada às possibilidades que os agentes possuem. E, esta produção, aponta para a seguinte afirmativa: "os registros ou as evidências da luta dos agentes históricos são o ponto de partida para entendermos os processos históricos" (BEZERRA, 2010, p. 43), ou seja, dois imigrantes italianos anarquistas podem ser alvo de um estudo sobre as migrações, o êxodo rural, a política e a jurisprudência, entre outros.

Quanto à ligação desta discussão com o Referencial Curricular de Cachoeira do Sul, é possível relacionar a todos os conceitos estruturantes propostos, que, no caso, são eles: "tempo, poder, trabalho, cidadania, cultura e identidade" (Cachoeira do Sul, 2011, p. 70). Destarte, Sacco e Vanzetti, enquanto trabalhadores reivindicam outro tipo de cidadania baseada na anarquia, que é, genericamente, uma ideologia que fundamenta as identidades dos operários que se aproximam do anarquismo através das sociabilidades, das leituras e/ou dos mundos do trabalho. Nos textos de Sacco e Vanzetti, o poder é debatido e transformado em uma relação horizontal, e não mais verticalizada conforme as suas reflexões sobre a sociedade capitalista.

A trajetória destes anarquistas pode ser relacionada ao seu "tempo", ou seja, a partir dos acontecimentos históricos marcantes do início do século XX. Desta maneira, poder-se-ia verificar as consequências da Primeira Guerra Mundial (19141918), da Revolução Russa (1917) e os efeitos desta nova fase mundial. Há, ainda, o predomínio econômico e político dos Estados Unidos da América frente ao ocidente e o declínio da hegemonia britânica nestes quesitos. Enfim, o caso Sacco e Vanzetti possibilita estudar as manifestações em vários países, noticiadas pelos jornais e fomentadas pelas agências de notícias.

\section{Considerações finais}

A discussão referente ao ensino de Geografia e História é determinante para destacar os perfis de educadores existentes. A questão não é restritamente os conteúdos a serem abordados, mas as formas, os meios e as intencionalidades que os professores ofertam aos educandos. Assim, pensa-se em uma pedagogia que viabiliza a autonomia dos estudantes como meio e fim do processo de ensinoaprendizagem.

Acredita-se, também, que as infinitas possibilidades de estudos que o caso Sacco e Vanzetti proporcionam, servem para outros inúmeros fatos históricos a serem apreendidos. No mesmo sentido, o estudo da geografia capacita à compreensão mais complexa a respeito das migrações e dos deslocamentos sociais ocorridos na história. Desta forma, Geografia e História são ciências que dialogam e que colaboram para a formação integral dos estudantes, em outras palavras, havendo a utilização dos vários recursos destacados neste artigo, oferta-se o trabalho com fontes digitalizadas de qualidades diversificadas. É, em outras palavras, uma oferta dirigida aos alunos que sugestiona a pesquisa e identificação com as linguagens e os recursos utilizados pelos veículos de comunicação.

Verificar a trajetória de Sacco e Vanzetti, as representações e os discursos relacionados à imagem desta dupla cria a oportunidade de historicizar as instituições jurídicas estadunidenses. E, um segundo ponto determinante, questionar a importância dos Direitos Humanos para os avanços da garantia de defesa dos cidadãos. Este "olhar histórico" deve possuir a qualidade comparativa, destarte, respeitando o passado e o presente com os seus valores e representações em "choque" para evitar o anacronismo histórico.

No Brasil, o caso Sacco e Vanzetti serviu de apoio aos grupos sociais que eram contrários à pena de morte. Fortaleceu, também, os grupos anarquistas e operários ligados aos sindicatos e associações da classe. Por fim, Bartolomeo Vanzetti e Nicola Sacco 
"ficaram" para a história como aqueles que tiveram o sonho de "fazer a América", mas fracassaram. Eles permanecem na memória anarquista como mártires sociais, ou, melhor, aqueles que enfrentaram e doaram a própria vida em nome da liberdade universal dos povos.

\section{Referências}

AGUIAR, Pedro. Por uma História do Jornalismo Internacional no Brasil. In: VI Encontro bNacional de História da Mídia, Anais, 2008 (CD-ROM). Niterói: Rede Alfredo de Carvalho, 2008.

AGUIAR, Pedro. Notas para uma História do Jornalismo de Agências. In: VII Encontro Nacional de História da Mídia - GT História do Jornalismo, Anais. Fortaleza, 2009.

BEZERRA, Holien Gonçalves. Ensino de História: conteúdos e conceitos básicos. In KARNAL, Leandro (org.). História na sala de aula: conceitos, práticas e propostas. São Paulo: Contexto, 2010.

BOYD-BARRET, Oliver. RANTANEN, Terhi. "News Agencies as News Sources: A Re-Evaluation" In: PATERSON, Chris; SREBERNY, Annabelle (orgs). International News in the 21st Century. Londres: John Libbey/University of Luton Press, 2004.

CACHOEIRA DO SUL. Secretaria Municipal de Educação. Referencial Curricular. Cachoeira do Sul, RS, 2011.

CARDOSO, Gustavo, MENDONÇA, Sandro, QUINTANILHA, Tiago Lima, PAISANA, Miguel. Estudo prospectivo para o futuro imediato das Agências de Notícias. OberCom - Observatório da Comunicação, Lisboa, Portugal, 2016.

CANNISTRARO, Philip V. Mussolini, Sacco-Vanzetti, and the anarchists: the transatlantic context. Chicago: The Journal of Modern History, mar. 1996, p. 31-62.

CHESNEAUX, Jean. Devemos fazer tábula rasa do passado? Sobre história e os historiadores. São Paulo: Ática, 1995.

FAST, Howard. Sacco e Vanzetti: a história de dois imigrantes italianos condenados à morte. Rio de Janeiro: BestBolso, 2009.

HELENE, Daniel Vieira. A História, seu ensino e sua aprendizagem: conhecimentos prévios e o pensar historicamente. Tese (doutorado em História), São Paulo, 2016.

HOBSBAWM, Eric. O século: vista aérea, um olhar panorâmico. In: A era dos extremos: O breve século XX, 1914-1991. $2^{\mathrm{a}}$ Ed. S. Paulo: Companhia das Letras, 1995, p. 447-462.

KARNAL, Leandro. Introdução. In: KARNAL, Leandro (org.). História na sala de aula: conceitos, práticas e propostas. São Paulo: Contexto, 2010.

LEFEBRE, Henri. The production of space. Oxford: Blackwell, 1991.

O direito à cidade. São Paulo: Centauro, 2001.

MATTELART, Armand. Comunicação-Mundo: história das técnicas e das estratégias. Petrópolis: Vozes, 1994.

MINISTÉRIO DA EDUCAÇÃO. Base Nacional Comum Curricular. Proposta Preliminar. Segunda Versão Revista. Brasil, 2016.

MOURA, Clóvis. Sacco e Vanzetti: o protesto brasileiro. São Paulo: Ed. Brasil Debates, 1979.

PALMA, Rogério da. TRUZZI, Oswaldo. Italianos em São Carlos (SP): começo ou fim de uma história? In: ELMIR, Claudio Pereira. WITT, Marcos Antônio (Orgs.). Imigração na América Latina: histórias de fracassos. São Leopoldo: Oikos; Editora Unisinos, 2014.

PATERSON, Chris. News Agency Dominance in International News on the Internet. In: SKINNER, D., COMPTON, J. and GASHER, M. (orgs.) Converging Media, Diverging Politics: A Political Economy of News in the United States and Canada. Lexington/Rowman and Littlefield, 2005. pp. 145-164. 24p.

PINSKY, Jaime. PINSKY, Carla Bassanezi. Por uma história prazerosa e consequente. In: KARNAL, Leandro (org.). História na sala de aula: conceitos, práticas e propostas. São Paulo: Contexto, 2010.

PORTER, Katherine Anne. Sacco e Vanzetti: um erro irreparável. Rio de Janeiro, Salamandra, 1978.

PUGLIELLI, Edoardo. Per la vita di Sacco e Vanzetti: le mobilitazioni popolari in Abruzzo e Molise (1921-1922). Chieti: Centro Studi Libertari Camillo Di Sciullo, 2013.

PURDY, Sean. O século americano. In: KARNAL, Leandro. PURDY, Sean, FERNANDES, Luiz Estevam [et al.]. História dos Estados Unidos: das origens ao século XXI. São Paulo: Contexto, 2007, pp. 173-276.

RUSSELL, Francis. A tragédia de Sacco e Vanzetti. Rio de Janeiro: Editora Civilização Brasileira, 1966.

Santos, Milton. A Natureza do Espaço: Técnica e Tempo, Razão e Emoção. São Paulo: Editora da Universidade de São Paulo, 2006. 
SCHMIDT, Maria Auxiliadora. CAINELLI, Marlene.

Ensinar história. São Paulo: Scipione, 2009.

TUDINI, Flavia. Sacco e Vanzetti: caso giudiziario o affaire? Diacronie [Online], $\mathrm{N}^{\circ}$ 14, 2 | 2013, documento 4, Messo online il 01 agosto 2013, consultato il 06 dicembre 2015. URL : http://diacronie.revues.org/160 